\title{
Resistencia en teoría: ¿final de una ilusión?
}

Recibido: 01/02/2011

\author{
Félix MARTÍN GUTIÉRREZ \\ Universidad Complutense de Madrid \\ felmar@filol.ucm.es
}

Aceptado: 04/05/2011

\begin{abstract}
RESUMEN
Este artículo trata de recoger las impresiones y sugerencias críticas provocadas por la lectura de Resistencia en teoría, una publicación que tiene el controvertido ensayo de Paul de Man como punto de partida. Precisamente es la relectura que hace el profesor Damaso López de este ensayo - una relectura bromista, abiertamente escéptica, reflexiva y profunda- lo que conduce a revisar detalladamente los presupuestos lingüísticos, y retóricos de la deconstrucción en America, de la teoría y práctica de la lectura deconstructiva y de su repercusión en la revisión actual de la historia literaria norteamericana. A raíz de esta revisión se examinan aquellos artículos de los investigadores jóvenes que plantean alternativas actuales significativas sobre aspectos importantes-género, sexualidad, ecocrítica, arte pictórico y visual--de la teoría literaria.
\end{abstract}

Palabras clave: Deconstrucción, lectura crítica, Paul de Man, resistencia.

\section{Resistencia en teoría: the end of dellusion?}

\begin{abstract}
This review essay tries to explore some impressions and suggestions provoked by Resistencia en teoria, an academic study which places Paul de Man's controversial essay as a starting point. Based on Dr. Damaso López introductory chapter-delightfully funny, provoking and openly sceptic of the relevance of de Man 's concept of resistence,--this essay brings to our attention some of the linguistic and rhetorical assumptions held by deconstruction in America, the practice of critical reading developed by Paul de Man and the expansion of deconstruction to other areas of critical thinking, especially to the revision of American literary history. At the same time, and connected with this aim the article reviews those essays published by young researchers which tackle significant issues of theoretical debates - gender, sexuality, ecocriticsm, painting and visual art- underlying the critical relevance of "resistance".
\end{abstract}

Keywords: Deconstruction, critical reading, Paul de Man, resistance.

SUMARIO: Pretexto 1. "Fashion Victims". 2. "Resistencia en teoria”. ¿Y en la práctica? 3. Más allá de la lectura "Deconstructiva". 4. Teorizar las rupturas.

DÁmASo LÓPEZ GARcía (Ed. General), Iñigo FERnÁNDEZ LOMANA, CRistinA SÁNCHEZ SOTO, EDUARDO VALLS OYARZUN, editores adjuntos.

Resistencia en teoría. Madrid, Editorial Verbum, 2010. ISBN: 978-84-7962-648-8 


\section{PRETEXTO}

No se alarme el lector. No vamos a predecir el colapso de la teoría literaria, ni registrar irreparables rupturas de gustos o modas, ni mucho menos recitar esa letanía agresiva --transgresión, subversión, ruptura, desmantelamiento, fragmentación, violencia, de-mistificación - que pregona el credo postmodernista y circula por los ambientes académicos aireando su retórica militante. Se trata tan sólo de "resistencia". Mejor dicho de imposibilidad de resistir. Y se trata de la osadía de un grupo de jóvenes investigadores que, respondiendo al compromiso contraído con el seminario Paradigmas de la ruptura en la cultura anglo-norteamericana, celebrado en la Universidad Complutense, plantean cuestiones en torno a la "resistencia en teoría" desde su escenario original (Paul de Man como epicentro) hasta sus ramificaciones estéticas y materiales más precintadas, incluidas las transmutaciones del género, o expandidas dialécticamente por las rupturas y subversiones del lenguaje, de la raza y hasta de la conciencia eco-crítica reciente. Ingenuamente tal vez confiesan los editores que los obstáculos para la organización del seminario les obligaron ya a adoptar ciertas tácticas "deconstructivas", pues podría haber sido este encuentro "una comprobación empírica de la inutilidad de las formas de ruptura o de disidencia (RT, 9)", motivada tal vez por la posible "indiferencia de los imposibles receptores de sus mensajes y también, cómo no, de la beligerancia de quienes pudieran oponerse a las formas de ruptura que se analizaron (19)". Es decir, que todas las cautelas son pocas, fueron pocas y serán pocas, especialmente si de teoría literaria se trata, o de su aplicación, o de su supervivencia en el mundillo multicultural actual. "Resistencia", puntualiza Wlad Godzich en su introducción a The Resistance to Theory (1986, XIII) de Paul de Man, es una propiedad del referente que le permite ser objeto del conocimiento del sujeto que somos nosotros. En teoría literaria su papel es sumamente importante, pues constituye una precondición para acceder cognitivamente al mundo sensible. Por ello las propuestas de lectura crítica que contiene este libro sondean el alcance de rupturas epistemológica a través de sus contextos materiales. No obstante, junto a interrogaciones suscitadas por el "que fue de la deconstrucción" (creo personalmente que sigue muy viva) hasta cómo reciclar la teoría literaria o dotarla de nueva entidad cultural lo más preocupante sigue siendo la práctica de una interpretación todavía subyugada por las maniobras de las metodologías críticas. ¿No ha sido esto último precisamente lo que ha intentado subvertir la deconstrucción? ¿No ha liberado al intérprete de la tiranía de las metodologías, vocabularios o sistemas críticos?

\section{1. "FASHION VICTIMS"}

Como los problemas tácticos que despejan los editores aterrizan directamente en el despertar de la conciencia crítica preciso es optar, - antes de ofrecer alguna contestación a esta pregunta - por recoger las impresiones y cautelas que expone brillantemente el Dr. Dámaso López en las páginas finales de su "Fashion Victims: 
las dificultades de la teoría”. No podía ser más claro el enunciado de este capítulo, ni más complejo el que acoge los doce ensayos. La incursión inicial sobre la deconstrucción de la tortilla de patatas y de la moda es realmente magistral, tanto por su calado irónico como por la serie de observaciones sobre la relegación de lo literario ante la avalancha de productos derivados, aptos para toda clase de "fashion victims". La elaboración minuciosa de estos productos y de sus "víctimas" no sólo revela un aproximación crítica sensiblemente escéptica hacia los efectos de la deconstrucción -valdría la pena saber porqué la concibe como escuela, porqué Paul de Man representa la orientación más específicamente literaria, o porqué cuestiona el alcance espistemológico de la lectura deconstructiva - sino que la diagnosis minuciosa y bromista que realiza aplica la terapia crítica más saludable para el momento actual. ¿Cómo no sonreír (o sonrojarse) al captar la antinomia entre crítica y texto a través de las diferencias entre parásito y anfitrión, insinuar si el "querer entender" es deseable o no, o imaginar la conversión de la "misma tortilla y los mismos volantes y tal vez el propio Harry" en el decenio de 1950 "en tortillas, volantes y Harry existencialistas (13)"? Al completarse esta excursión por la "Espuma de patatas", la Pasarela de Cibeles del 2003, la película de Woody Allen ( Deconstructing Harry, 1997), por De la gramatología o los "trend setters" californianos (17) haría bien el lector en recalar en la tradición satírica británica y evocar aquella sentencia memorable de Tristam Shandy: "Of all the cants that are canted in this canting world,--though the cant of the hypocrites may be the worst,--the cant of criticism is the most tormenting" (Tristam Shandy, vol.III, chap.12).

Resistencia en teoría condensa y analiza, efectivamente, uno de los ensayos más importantes de Paul De Man, The Resistence to Theory(1982) cuya relectura en el contexto crítico actual merecería serias reflexiones, no sólo por la inercia estructuralista que ha ejercido la lingüística sobre la teoría literaria (léase Structural Poetics,1975, de Jonathan Culler), sino por la suerte de otros modos de lectura desligados de la ideología romántica. Por otra parte, Resistencia en teoría facilita ironizar sobre cada uno de los dos términos: ¿Qué clase de resistencia? ¿O qué teoría? ¿O cómo calibrar si se trata de una resistencia en teoría y no en la práctica, trátese de teorizar, analizar o actuar? Por ejemplo la dieta pobre de America Latina que nos prepara Mercedes Replinger en su recorrido por países de materiales artísticos precarios nos ofrece un menú exquisito y abundante para dar sentido a esta paradoja: el viaje de desfallecimiento de Artur Barrio, nos dice, "no intentaba torturar el cuerpo o negarlo, sino todo lo contrario, intensificar las sensaciones y las percepciones de una situación que debía ser el material y la realidad del artista"(45). He aquí la resistencia hecha carne, palabra, imagen y paradigma interpretativo. Unas rupturas profundas que colocan las obras de Victor Grippo, Cildo Meireles, Ana Bellla Geiger, Marta Minujin y Artur Barrio como monumentos imperecederos de la arqueología artística latinoamericana, ideológicamente autónomos y limpios de ingredientes o especias estéticas occidentales.

Como ya hemos apuntado "Fashion victims: las dificultades de la teoría" deja al lector las puertas abiertas para discriminar con tacto sobre la lingüística de la literalidad, la confrontación e incorporación de las ideologías a la lectura 
deconstructiva y sobre todo la compleja articulación de la teoría de la literatura, un área que el Dr. Dámaso López desea situar dentro de un espectro humanístico más amplio que el examinado por Paul de Man. La excursión por el texto de Paul de Man es completa y predictiva. La serie de interrogaciones y conjeturas que cierran el ensayo podrían someterse al filtro de la sospecha que él mismo recoge sobre Paul Ricoeur y la fundamentación teórica de la deconstrucción. La perplejidad que siguen suscitando los problemas en torno al alcance de la transgresión ideológica, la verdadera aportación de la deconstrucción a la teoría de la literatura, o la revisión del canon se desliza libremente por la textura interrogativa de esos párrafos. Dado el tono burlón que destila todo el ensayo la comparación del canon con "un asunto de disputa sindical" la hubieran querido para sí tanto Hume (una medida justa para su teoría del gusto) como Harold Bloom, afanado en equilibrar mecanismos defensivos con figuras retóricas.

\section{2. "RESISTENCIA EN TEORIA". ¿Y EN LA PRÁCTICA?}

Hay otra clase de consideraciones que, como el mismo autor reconoce, "son más fáciles de exponer pero más difíciles de aceptar". Antes de recordarlas me permito traer a cuento las líneas que cierran el artículo de Paul de Man. "Nada puede superar la resistencia en teoría, pues la teoría es esta resistencia. Cuanto más elevados sean los objetivos y mejor los métodos de la teoría literaria, menos posible será. Y sin embargo la teoría literaria no está en peligro de hundirse; no puede sino florecer, y cuanto más resista más florecerá, pues el lenguaje que habla es el de la autoresistencia (de Man 1982, 20)". Precisamente es esta defensa categórica de la autoresistencia, aparentemente inseparable de una "autocrítica radical", lo que pudo provocar la retirada del artículo de la MLA y no razones o presiones de posiciones conservadoras e institucionales. A tenor de las críticas que Paul de Man recibió por parte de algunos intelectuales norteamericanos, tanto radicales como conservadores, su defensa de la "resistencia en teoría" señaló un cambio de rumbo que consolidaría su defensa de la metafísica humanista, o de una tradición estéticamente ordenada y compartida, tal vez sin saberlo, con la prevaleciente en Estados Unidos en el mundo académico (Harold Bloom, Cleanth Brooks, Murray Krieger, Morse Peckham, Wayne C.Booth o Kenneth Burke, por ejemplo). Su muerte en 1983 permitió recomponer una trayectoria crítica ostensiblemente escéptica y desencantada, cuya revelación produjo cierta hostilidad en el campo marxista. Frank Lentrichia, por ejemplo, llegó a sugerir que toda la obra de Paul de Man contenía un debate encubierto contra el marxismo.

La obra crítica de Paul de Man es un exponente cabal de las contradicciones que resalta el Dr. Dámaso López, especialmente si de resistencia crítica e ideológica se trata. Dudo, sin embargo, que haya llegado el momento de llevar a la deconstrucción al tribunal de la historia y solicitar la absolución de sus responsables por más ceguera ideológica o política que hayan mostrado. El caso de Paul de Man no agota obviamente las contradicciones de la deconstrucción en América, a pesar de su 
fidelidad a Derrida. Más aún, su propuesta de una ética de la lectura lleva la práctica interpretativa más allá del "close reading", alentada por unas formas de resistencia que combinan la producida institucionalmente con la elaborada en los procesos de lectura articulados por prejuicios, expectativas, horizontes y otros elementos psicológicos. A decir verdad puede uno preguntarse cómo es posible que el grupo de Yale fuera considerado por bastantes intelectuales como un obstáculo insalvable para que América pudiera ofrecer alternativas realmente teóricas ante la invasión del estructuralismo y de la deconstrucción franceses. Un cruce de prejuicios y de resistencias que hablan muy claro del clima de cruzada intelectual que causó la deconstrucción en Norteamérica.

No olvidemos que si de resistencias se trata la deconstrucción centrada en el grupo de Yale protagonizó varias: Paul de Man frente a las prácticas interpretativas de Hillis Miller y Geoffrey Hartman, la de estos tres frente a la postura de Harold Bloom y la doble de todo el grupo frente a la de los más radicales (Paul Bové, Joseph Riddell, Edward Said), o a la tradición dominante en el mundo académico norteamericano. No suele olvidar el lector que el riesgo de convertir la deconstrucción en mero ejercicio retórico, en una forma de leer desbocada hacia simples aporías, acompañó la recepción de Of Gramatology (1976) de Derrida, Allegories of Reading (1979 de Paul de Man y Criticism in the Wilderness (1980) de Hartman. El propio Paul de Man temía ya en 1979 que este modo de lectura crítica deviniera en interpretación hermenéutica, proclive ésta a salirse de la esfera del lenguaje y a establecer relaciones con elementos externos a él (la sociedad, la naturaleza, Dios, el yo, la historia). Y menos aún podemos ignorar que la resistencia a la teoría ocupó una espacio amplio en todo el país, demarcado por un lado por los intelectuales más conservadores (René Wellek, W. Jackson Bate, John Searle, Nathan Scott, entre otros), que tachaban esas prácticas retóricas de nihilistas, inmorales o carentes de valores culturales, y por otro por la izquierda (Edward Said, Fredric Jameson, Jeffrey Mehlman, Frank Lentrichia), presta a denunciar ese tipo de lecturas críticas por su desconexión con la historia, su debilidad ideológica y falta de compromiso activo en política.

\section{MÁS ALLA DE LA LECTURA "DECONSTRUCTIVA"}

Hasta qué punto la experiencia de la lectura crítica ha sido el fulcro interpretativo de la deconstrucción en América y la revitalización de la teoría literaria nos llevaría a ver cómo tanto Paul de Man como Hillis Miller han inyectado dosis de elementos éticos a sus propias lecturas. Hillis Miller, por ejemplo, en "The Ethics of Reading" (1987, 338-339) vuelve a insistir en que la lectura retórica, por sofisticada que parezca, es imprescindible para realizar el estudio propiamente humanístico que requieren la literatura, la historia, o la filosofía, por ejemplo, y, por otro, que la teoría literaria puede ser un instrumento eficaz para responder a las condiciones culturales, económicas, institucionales y tecnológicas del presente (Miller 1987:338-40). Paul de Man, por su parte, recuerda en Resistance to theory que el estudio de textos literarios depende necesariamente del acto de leer críticamente y que su dimensión ética va a 
ligada estrechamente a los procesos epistemológicos activados en ese acto, tal y como los describe en su introducción al libro de Carol Jacobs, The Disimulating Harmony. La fidelidad de Paul de Man a la interpretación deconstructiva fue tal que, como revelaría Hillis Miller, llegó a afirmar que la función de la crítica en un futuro próximo protagonizaría una especie de apropiación imperialista de toda la literatura mediante el método de la lectura retórica denominada "deconstrucción". Su concepción de estrategia retórica, no obstante, exhibía una ambivalencia marcada entre los sistemas de tropos dentro del texto y la proyección persuasiva, externa al texto, propia de la retórica clásica. Por lo tanto, como había mostrado en Allegories of Reading la intersección perturbadora entre tropo y persuasión arbitraba la "indeterminación del texto", conjugando la estructura gramatical con el nivel figurativo o tropológico (de Man 1979:IX)

Algunas dificultades de la teoría de la deconstrucción que diagnostica el Dr. Dámaso López en este primer capitulo pueden despejarse desde perspectivas históricas, especialmente si nos inquieta el pesimismo escéptico del presente. La "agridulce invitación" a la resistencia que lanza en las últimas líneas puede tomarse literalmente: sobrevolar el escepticismo esperando que los frutos de la deconstrucción maduren, aun aceptando que será muy difícil "volver a creer que se ha salido de la pasarela de los desfiles de moda (32). La invitación, ironías aparte, coloca estratégicamente al lector ante las alternativas críticas que ensayan los otros artículos del libro. Ni que decir tiene que la mayoría de ellas nos obligan a desfilar por pasarelas ya recorridas, aun alejadas lógicamente de la deconstrucción. Es necesario, sin embargo, advertir que la variedad y disparidad de aproximaciones que contiene esta colección de ensayos pone en evidencia precisamente cómo las nuevas teorías críticas no son aplicables como vocabularios críticos separados de sus contextos discursivos, o cómo, la interpretación no es una técnica o un esquema de ideas separable de las formas de la escritura, sino prácticas discursivas complejas, predominantemente atentas al efecto político de esas prácticas. Es decir que, aun obligados a pasar por una misma pasarela, las modas que exhiben revelan cómo se puede ascender de "fashion victim" a "trend-setter".

Antes de examinar algunos de estas transformaciones me parece imprescindible recordar cómo fue la expansión de lo que Derrida entiende por "escritura" en cuanto mapa de todas las formas de inscripción o campo inconmensurable de textos escritos lo que propició, entre otros factores, el establecimiento de diálogos críticos e intertexutales entre diferentes parcelas del feminismo, del marxismo, de la semiótica, del colonialismo o de la historia de la recepción. La expansión de la deconstrucción hacia otros terrenos críticos fue iniciada ya a mitad de los setenta, especialmente por críticos como Edward Said, Gayatri Spivak, John Brenkman, Michael Ryan o Frank Lentrichia, conscientes de que el formalismo analítico o la "regresión infinita" que producía la indeterminación textual requerían una contextualización histórica, social o política. ¿Cómo entender la radicalidad política o social a partir de análisis que multiplican hasta el infinito esa indeterminación? ¿Dónde situar la materialidad misma de la historia literaria? Al ensayar estos críticos una articulación viable entre deconstrucción, feminismo y marxismo la función de la teoría vino a reclamar una 
justificación nueva. Hillis Miller en su "Pressidential Address 1986"(315) rendirá, tributo a algunos de los miembros más destacados de lo que podríamos llamar segunda generación de de-constructivistas norteamericanos (Michel Sprinker, Cynthia Chaise, John Rowe, Jonathan Arac, Michael Ryan, Gayatri Spivak, Suzanne Gearhart o David Carol), cuya aportación a la revisión textual de la historia social, política y literaria norteamericana ha cambiado el curso de la teoría literaria en este país. ¿Quién ha proporcionado si no los perfiles más estimulantes de los clásicos norteamericanos, de su historia literaria, de sus ideologías y lenguajes, de sus geografías interculturales?.

Como he adelantado más arriba la invitación agridulce del Dr. Dámaso López a la resistencia del artículo de Paul de Man convendría trasladarla a la lectura de los ensayos de este libro. No obstante, y como no deja cabo suelto esta diagnosis crítica, llama la atención una cuestión que el profesor Dámaso López plantea como si no esperara respuesta. Antes de haber llegado a esta situación de pesimismo, se pregunta, “¿cómo eran las cosas?” Es innegable que esta pregunta conduce al texto citado de Paul de Man. A título puramente informativo, sin embargo, valdría la pena evocar el contexto historiado que puede aclarar la suerte de la teoría literaria, sin necesidad de buscar causas o razones explicativas. Nos queda ya algo lejano este contexto, pero 1982 efectivamente culmina un período de entusiasmo académico por la deconstrucción que hizo olvidar la devastadora intervención de Jacques Derrida en 1966 contra su compatriota Lévi-Strauss en la universidad de John Hopkins. Por esta universidad, como es sabido, entró la deconstrucción francesa en Estados Unidos, precedida por insignes visitantes del estructuralismo galo a esta institución ( George Poulet, Gerard Genette, Jean Starobinski, René Girard), una oleada intelectual que Richard Macksey en Velocities of Change(1974) califica de vertiginosa, a la luz de su precursora The Structuralist Controversy(1970). Si se desea recorrer el puente que tendieron en los sesenta las obras de Barthes, Foucault, Lacan, Todorov, Deleuze, Greimas, Althuser, Genette o Dubrosky entre Europa y Norteamerica, por ejemplo, y captar la respuesta norteamericana de los setenta (Hartman, Culler, Holland, Miller, Jameson, de Man, Rifaterre, Said, Fish, entre otros) se observará cómo las corrientes más profundas de la deconstrucción vinieron a inundar un territorio todavía fertilizado por los "New Critics". Puede asimismo cotejarse este trasvase intelectual anotando la aparición de las revistas Diacritics, New Literary History, Glyph, o Sub-stance, o Representations. Las corrientes teóricas se hicieron visibles en las universidades prestigiosas, dejando todavía oír las voces de los maestros de la historia literaria (Amado Alonso, Leo Spitzer, René Wellek, W. K. Wimsatt, Mark Schorer). La fiebre de "análisis textuales", sin embargo, iría desplazando gradualmente a la detección de estructuras, funciones, caracteres, "plots" y demás jerga estructuralista.

Una mirada retrospectiva a la introducción de la deconstrucción en América pasa inevitablemente por este cambio pedagógico, pues es manifiesto que la conexión entre teoría y enseñanza carecía de sustento intelectual. El mismo ensayo de Paul de Man, Resistance to Theory aparecería publicado en el número 63 de Yale French Studies (The Pedagogical Imperative) prologado con signos de frustración reconocida por no haber alcanzado los objetivos pedagógicos previstos por la MLA. Debe 
entenderse que la preocupación didáctica fue un impulso decisivo para la implantación de la lectura crítica deconstructiva, pues la práctica introducida por Derrida cuestionaba la posibilidad de producir una configuración unificada de lectores y lectura. Sigue produciendo de hecho no pocos dolores de cabeza ver si la lectura cuestiona o dobla los procesos de identificación, si el acierto o desacierto traiciona al texto por exceso de fidelidad o viceversa, si crea conflictos inexcusables entre lo singular (texto) y lo plural (nosotros), si restaura significados que no parecen inherentes al texto, o si las diferencias textuales no encuentran atribución o sentido alguno. ¿Cómo podemos leer, se preguntaría Shoshana Felman, lo que es diferente a sí mismo? ¿Cómo negarse a buscar el sentido del texto y entretenernos en dejar de hallar sentido?

Semejante "resistencia" al proceso de lectura dificulta seriamente transformarla en material pedagógico rubricado por una teoría literaria específica. Por ello es comprensible la inquietud del estamento académico sobre el futuro de la teoría literaria, un futuro que se ha hecho presente en proporciones inimaginables desde que Ralph Cohen (The Future of Literary Theory, 1989), Cary Nelson (Theory in the Classroom, 19869 ) o Joseph Natoli Tracing Literary Theory, 1987) propulsaran la utilización de las antologías para incorporar nuevas aproximaciones teóricas. Aunque no es éste el lugar para exponer los efectos de la pedagogía de la deconstrucción en Norteamérica, sí vale la pena subrayar que las prácticas docentes espoleadas por la deconstrucción han contribuido decisivamente al cambio de actitudes del intérprete frente al texto, a adoptar tácticas creativamente dialécticas, a conversar inteligentemente con él y explorar la historia y la estructura lingüística.

\section{TEORIZAR LAS RUPTURAS}

Una sensibilización pedagógica como la pretendida por la deconstrucción ha chocado frecuentemente con la clase de indagación que estimula o produce el estudio ideológico o cultural. Resulta problemático ir contracorriente de la moda crítica en áreas en las que la politización ha condicionado la aplicación de pautas teóricas de confrontación, procedimientos diseñados por el resentimiento o recuperación de tradiciones literarias perdidas. Estas dificultades nos acechan no sólo al examinar áreas explícitamente conflictivas -sí, mencionemos la teoría literaria feminista, cuestiones del género, política sexual, teoría postcolonial, sistemas sociales, guerras culturales, -sino también cuando abordamos problemas multiculturales e interculturales. Como advierte Ian Hunter, es preciso entender cómo la teoría literaria se relaciona con la política empírica y entrever que lo importante es descifrar si la variante crítica elegida nos ayuda a descifrar nuestra identidad ética y reconcilia dialécticamente los fragmentos con la humanidad futura. La respuesta, añade, es "que el discurso literario político es de hecho un medio para convertir las situaciones políticas en ocasiones hermenéuticas." (Hunter 1996, 1129).

Esta conversión puede despejar numerosas rupturas del panorama literario si se acepta que la política y sus discursos son efectivamente el marco de referencia 
operativo. Pero los muros levantados por los lenguajes críticos de la raza, de clase o de género hacen difícil tal procedimiento hermenéutico. Recordemos cómo los diálogos críticos arbitrados por tácticas de oposición generan conflictos dialécticos a veces interminables, como podemos extraer incluso de una política interpretativa plural o conciliadora, o como suele evocarse a través de las polémicas más encendidas del postcolonialismo. Los artículos que componen Resistencia en teoría esquivan esta vía. La escogida en "El cuerpo en casa: Imágenes del desarraigo en las artes plásticas contemporáneas Anglo-Norteamericanas" por Carmen Bernárdez, no sólo traza una secuencia histórica de rupturas estéticas sino que interpreta las que han llevado a cabo David Hockey, Francis Bacon, Edward Hopper, Richard Hamilton, Georgia O'Keefe , Claes Oldenburg y Rauschenberg expandiendo los ángulos visuales que requiere esta ruptura. La concentración en un objeto concreto como la casa y las variaciones perceptivas y visuales que comenta Carmen Bernárdez refuerzan la visión inequívoca de que el arte juega con sus propias rupturas. El espectro crítico que ha desarrollado la cultura visual es tan extenso que las variables introducidas en los conceptos "especulación", "observación", "reflexión", "perspectiva" y "focalización" suelen transferirse con toda naturalidad al campo narratológico.

La reflexión que propone Cristina Sánchez Soto en Resistencia en teoría sobre "De la construcción social a la performatividad de las identidades del género" aproxima su análisis al lector consciente del dilema apuntado más arriba. La presentación inicial de sus motivaciones personales, afectadas por la realidad académica, sirven de trampolín para contrastar ideológicamente las concepciones sobre el género planteadas por Judith Butler y Teresa Ebert, un contraste significativo y esclarecedor en los momentos actuales. No es la exhaustividad especulativa sobre los planteamientos de estas dos intelectuales-muy prolífica en estudios especializados-- ni su aplicación a "Mischief" de Alice Monroe lo que da relieve a esta ocasión textual y filosófica, sino la validación de su línea hermenéutica. Extraña la reacción a la cita de Terry Eagleton, precisamente la alternativa exacta a la que ella se dirige: que ante la vida real (¿Cómo me hago a mí misma al hablar? ) debe retirarse la interpretación del texto. ¿Dónde, sin embargo, queda expuesta la ruptura? ¿En las diferencias entre una performatividad constructivista y otra radicalmente materialista? $¿ \mathrm{O}$ en el hecho de dar por hecho que sus respectivas posiciones (Judith y Ebert) son anti-esencialistas? Esta confrontación, evidentemente, podría adoptar otra vía descriptiva, otra forma de resistencia dialéctica, como la que justifica el análisis de la novela The Five-Dwellers de Margaret Laurence por parte de María del Carmen Saura Marín. Pero aquí la subversión formal de la novela transcurre por los cauces paralelos de la teoría feminista postmoderna sobre la identidad.

No es mi propósito comentar cada uno de los artículos de Resistencia en teoría dentro de un mismo cuadro teórico. Tan sólo detectar la incidencia rupturista y su justificación teórica. El cuadro que presenta Carolina Recio Velázquez en "La agresión social y sus mitos" responde a una promesa investigadora que deja entrever mundos fascinantes y provocadores, muy justificados ideológicamente. Las obras de Ann Cahill, Venable Raine, Katherine Harrison, Janice Haaken que examina 
componen un cuadro espectral que resulta comprometedor en varios sentidos: el de las bases mitológicas de la violencia sexual, el de la sacralización institucional del cuerpo violado y el de la visualización por parte del lector. La descripción de cada novela trasluce verbalmente la seducción, pero no sus efectos, asunto que requerirá acceder al psicoanálisis. El cómo es más importante que el qué, en este caso, pues resistir la mortificación de la carne en aras de lo sagrado y contemplar la agresión sexual ritualizada no es un espectáculo tolerable. No es ese el caso de "El cognitivismo computacional en la "Sociedad de la información: el cyborgfeminista" de Belén González Morales, una relectura del "Manifiesto para Cyborgs" de Haraway que llega algo tarde. Produce cierta decepción comprobar cómo la reducción del sujeto femenino a pura abstracción, a software físico y tecnológico pueda concebirse como propuesta liberadora para la mujer.

"Políticas del desgarro, poéticas de la carne", de Iñigo F. Lomana, se asoma osadamente, vía "Saint Foucault", a los procesos de reconceptualización del cuerpo como consecuencia de su interacción con la tecnología. Es este un problema crítico en la investigación científica actual, que Iñigo aborda con las armas foucaultianas a su alcance. A pesar de la elaboración fragmentaria y evocativa que presentan los conceptos de "aparato biopolítico", "régimen disciplinario"o "hipercorporeidad" las poéticas del desgarro aparecen donde era de suponer: en los códigos visuales de la pornografía, en espacios artísticos o discursivos estéticamente transgresores. De ahí que el análisis de las obras de Gina Pane y Chris Burden, o el recuerdo del Síndrome de Inmunodeficiencia Adquirida conduzcan por la vía de la violencia visual a la confrontación de la ruptura estética, es decir, del desgarro . La teoría foucaultiana, se ha sugerido, conjuga la sexualidad y la materialidad del arte ad infinitum .

Una genealogía convincente de las bases ideológicas del ecologismo actual cierra la colección que nos ocupa. Aunque insertada en el apartado de revisiones del Canon, la aportación de Eduardo Valls, "Nueva sublimación política de la Naturaleza o cómo The Whale pasó al siglo XXI", traza filosóficamente las premisas nietzcheanas del ecologismo y reinterpreta Moby Dick como entidad textual ecosistémica. Ambos objetivos merecen destacarse, pues de uno a otro media una ruptura históricamente significativa, explorada paso a paso a través de la reevaluación biocéntrica que postulara Nietzche de la relación hombre-naturaleza, la teoría ecocrítica norteamericana y el análisis textual de la novela, particularmente esclarecedor en el análisis del capitulo XXXII. La minuciosa revisión filológica de ese capítulo, de la elaboración taxonómica de Ishamel, de su tramado ensayístico, científico y cultural, así como de la mitificación y simbolización de la ballena corroboran la predicción final de que representa el paradigma de ecotexto. La ruptura toma cuerpo como paradigma interpretativo: "Insisto", nos dice Eduardo Valls, "la novela no es "A book about whales", sino "a whale of a book". 


\section{REFERENCIAS}

De Man, Paul (1979) : Allegories of Reading: Figural Language in Rousseau, Nietzsche, Rilke and Proust. New Haven: Yale University Press.

De Man, Paul (1982) : "The Resistance to Theory", en The Pedagogical Imperative: Teaching as a Literary Genre. Yale French Studies, no 63. pp. 3-21.

De Man, Paul (1986) : The Resistance to Theory. Theory and History of Literature, vol. 33. Intro. de Wlad Godzich. Manchester University Press.

Hunter, Ian (1996) : "Literary Theory in Civil Life", South Atlantic Quaterly 95, n 4, pp.1107-1131.

Miller, J. Hillis (1991) : Theory Now and Then. New York, Harvester Wheatsheaf. 